\title{
Particle size effects for carbon nanofiber supported platinum and ruthenium catalysts for the selective hydrogenation of cinnamaldehyde
}

\author{
Arie J. Plomp ${ }^{\text {a }}$, Heli Vuori ${ }^{\text {a,b }}$, A. Outi I. Krause ${ }^{\mathrm{b}}$, Krijn P. de Jong ${ }^{\text {a }}$, Johannes H. Bitter ${ }^{\mathrm{a}, *}$ \\ a Inorganic Chemistry and Catalysis, Utrecht University, P.O. Box 80083, 3508 TB Utrecht, The Netherlands \\ ${ }^{\mathrm{b}}$ Laboratory of Industrial Chemistry, Helsinki University of Technology, P.O. Box 6100, FIN-02015 Espoo, Finland
}

\section{A R T I C LE I N F O}

Article history:

Received 1 July 2008

Received in revised form 20 August 2008

Accepted 20 August 2008

Available online 28 August 2008

\section{Keywords:}

Platinum catalysts

Ruthenium catalysts

Carbon nanofibers

Particle size effect

Cinnamaldehyde hydrogenation

\begin{abstract}
A B S T R A C T
The selective hydrogenation of cinnamaldehyde was studied over carbon nanofibers (CNF) supported platinum and ruthenium catalysts. The catalysts differed independently in their metal particle sizes and amount of acidic oxygen groups on the CNF surface. For the catalysts with oxygen on the CNF surface, the larger metal particles $(\sim 3.5 \mathrm{~nm}$ ) displayed the highest selectivity towards cinnamyl alcohol. Surprisingly, when the oxygen groups were removed from the catalyst surface, the smaller particles $(\sim 2.0 \mathrm{~nm})$ exhibited the highest selectivity to cinnamyl alcohol. Also the hydrogenation activity increased for all catalysts after oxygen removal. A model is proposed to account for the role of the metal particle size and oxygen surface groups in the hydrogenation of cinnamaldehyde.
\end{abstract}

(C) 2008 Elsevier B.V. All rights reserved.

\section{Introduction}

The hydrogenation of cinnamaldehyde can proceed via two pathways, i.e. via the formation of cinnamyl alcohol or via the formation of hydrocinnamaldehyde. In both cases the final product is hydrocinnamyl alcohol. The reaction via hydrocinnamaldehyde is thermodynamically more favorable, however the most desired product is the partially hydrogenated product cinnamyl alcohol $[1,2]$. The selectivity towards cinnamyl alcohol using platinum or ruthenium-based catalysts seems to depend on the metal particle and the selectivity increased with increasing metal particle size [1,3-9]. Giroir-Fendler et al. [5] attributed this particle size effect to a directing effect of the phenyl group. The authors proposed that the phenyl group is repelled by the metal surface in that way hampering the $\mathrm{C}=\mathrm{C}$ bond to approach the metal surface. Therefore, only the $\mathrm{C}=\mathrm{O}$ bond can approach the metal resulting in a higher selectivity for $\mathrm{C}=\mathrm{O}$ bond hydrogenation (see Fig. 1 ). In contrast, on small particles the phenyl ring does not interact with the metal surface and therefore both the $\mathrm{C}=\mathrm{O}$ and the $\mathrm{C}=\mathrm{C}$ bond can reach the metal surface and become hydrogenated. Alternatively, Galvagno et al. [8] hypothesized that the relative amounts of corners, edges and faces exposed to the reactants vary as function

\footnotetext{
* Corresponding author. Tel.: +31 30 2536778; fax: +31 302511027

E-mail address: J.H.Bitter@uu.nl (J.H. Bitter).
}

of the particle size. The atoms in different crystallographic positions can have different catalytic properties, resulting in different selectivities and activities as a function of the particle size. The particle size effect is also observed when using cobalt catalysts for cinnamaldehyde and crotonaldehyde hydrogenations and when using platinum catalysts for the crotonaldehyde hydrogenation [10,11]. On the other hand, it is not observed for citral or acrolein hydrogenations on ruthenium catalysts $[6,12,13]$.

Some studies addressed the particle size effect on platinum supported on carbon-based supports [4,5]. In those studies, the particle size was varied by using different calcination or reduction temperatures after catalyst preparation. Unfortunately, these treatments do not only influence the metal particle sizes, but the amount of oxygen groups on the surface of the carbon support is modified as well. The latter might have a significant influence on the catalytic performance of carbon based catalysts as was for example shown by Toebes et al. $[14,15]$. In these studies, it was shown that the activity of Pt/CNF catalysts significantly increased after removing oxygen groups from the support surface, although the selectivity to the desired cinnamyl alcohol decreased. Therefore we report here a systematic study on the influence of oxygen surface groups on the particle size effect of both platinum and ruthenium supported on CNF.

CNF are inert and pure graphite-like materials with a high specific surface area [16]. Therefore, CNF can be used conveniently as a model to study supported, catalytically active nanoparticles 


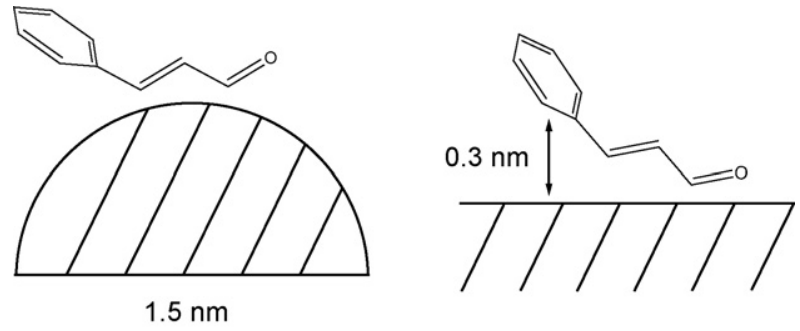

Fig. 1. Adsorption of cinnamaldehyde on a small metal particle (left) and a large non-curved particle (right). (Reproduced from Giroir-Fendler et al. [5] with kind permission of Springer Science and Business Media).

[17]. In the current study, platinum and ruthenium particle size effects were investigated for the selective hydrogenation of cinnamaldehyde using CNF as support. Samples which differed in their platinum or ruthenium particle size (1-3 and 2-6 $\mathrm{nm}$ for both metals) and amount of acidic oxygen groups on the CNF surface, either 0.17 groups $\mathrm{nm}^{-2}$ or without oxygen surface groups, were studied. We opted for varying the particle size by preparing the catalysts in two different ways, i.e. atomic layer deposition (ALD) and homogeneous deposition precipitation (HDP). Via heat-treatments in inert conditions, the oxygen surface groups could be removed completely, while the metal particle sizes were not affected [14].

\section{Experimental}

The $\mathrm{Ni} / \mathrm{SiO}_{2}$ (20 wt\%) growth catalyst was prepared via HDP using $17.0 \mathrm{~g}$ silica (Degussa; Aerosil 200), $21.1 \mathrm{~g}$ nickel nitrate hexahydrate (Acros; 99\%) and $13.9 \mathrm{~g}$ urea (Acros; p.a.) in $1 \mathrm{~L}$ demineralized water according to an earlier described procedure [18].

CNF growth was adapted from Toebes et al. [18]. For CNF growth the $\mathrm{Ni} / \mathrm{SiO}_{2}$ catalyst $(2 \mathrm{~g}$ ) was loaded in a quartz boat and placed horizontally in a tubular furnace. The catalyst was reduced in $\mathrm{H}_{2} / \mathrm{N}_{2}$ mixture $(276 / 1026 \mathrm{~mL} / \mathrm{min})$ at $973 \mathrm{~K}$ (ramp $5 \mathrm{~K} / \mathrm{min})$ for $2 \mathrm{~h}$ at $3.4-$ 3.8 bar total pressure. Next, the temperature was decreased to $823 \mathrm{~K}$ and the CNF were grown for $24 \mathrm{~h}$ from $\mathrm{CO} / \mathrm{H}_{2} / \mathrm{N}_{2}(441 / 148 / 704 \mathrm{~mL} /$ $\mathrm{min})$ at 3.4-3.8 bar total pressure. The raw material $(30 \mathrm{~g})$ was collected and refluxed for $1 \mathrm{~h}$ in an aqueous $\mathrm{KOH}$ solution $(1 \mathrm{M}$; $0.6 \mathrm{~L}$ ) solution to remove the $\mathrm{SiO}_{2}$. After washing, the material was refluxed for $2 \mathrm{~h}$ in concentrated nitric acid (0.6 L; Merck; 65\%) and filtered to remove exposed nickel and introduce oxygen-containing groups on the CNF surface. This material is referred to as CNF-ox. Finally, the material was washed three times with demineralized water and dried overnight at $393 \mathrm{~K}$.

Platinum [14] and ruthenium [19] were deposited on CNF-ox using HDP as described before. The prepared catalysts were reduced at $473 \mathrm{~K}$ for $1 \mathrm{~h}$ ( $\operatorname{ramp} 5 \mathrm{~K} / \mathrm{min}$ ) in $10 \% \mathrm{v} / \mathrm{v} \mathrm{H}_{2} / \mathrm{N}_{2}(100 \mathrm{~mL} /$ $\mathrm{min}$ ) and subsequently crushed and sieved in a fraction of 25$90 \mu \mathrm{m}$. The resulting platinum catalyst was denoted as $\mathrm{Pt} / \mathrm{CNF}$ (HDP). Part of the platinum and ruthenium catalysts was treated in $\mathrm{N}_{2}$-flow at $973 \mathrm{~K}$ for $2 \mathrm{~h}(5 \mathrm{~K} / \mathrm{min})$ to remove the oxygen surface groups $[14,19]$. The resulting catalysts are denoted as Pt/CNF-973 (HDP) and Ru/CNF-973 (HDP).

Platinum and ruthenium on CNF-ox catalysts were also prepared using ALD in a flow-type F-120 reactor (ASM Microchemistry) that operated at a reduced pressure of 5-10 mbar. CNFox ( $2.5 \mathrm{~g})$ were placed in a quartz reactor and heated to $473 \mathrm{~K}$. Subsequently, $1.2 \mathrm{~g} \mathrm{Ru}_{3}(\mathrm{CO})_{12}$ or $\mathrm{Pt}(\mathrm{acac})_{2}$ (Volatec Oy) was evaporated at $413 \mathrm{~K}$ and $453 \mathrm{~K}$ respectively in flowing nitrogen and led over CNF-ox for at least $3 \mathrm{~h}$ to ensure complete reaction. After the reaction, the excess reactants and gaseous by-products were removed by purging with nitrogen. The prepared catalysts were reduced at $473 \mathrm{~K}$ for $1 \mathrm{~h}\left(\operatorname{ramp} 5 \mathrm{~K} / \mathrm{min}\right.$ ) in $10 \% \mathrm{v} / \mathrm{v} \mathrm{H}_{2} / \mathrm{N}_{2}$
$(100 \mathrm{~mL} / \mathrm{min})$ and subsequently crushed and sieved in a fraction of 25-90 $\mu \mathrm{m}$. The resulting platinum catalyst was denoted as Pt/CNF (ALD). Part of the platinum and ruthenium catalysts was treated in $\mathrm{N}_{2}$-flow at $973 \mathrm{~K}$ for $2 \mathrm{~h}(5 \mathrm{~K} / \mathrm{min})$ to remove the oxygen surface groups $[14,19]$. The resulting catalysts are denoted as Pt/CNF-973 (ALD) and Ru/CNF-973 (ALD).

Cinnamaldehyde hydrogenation was performed at $313 \mathrm{~K}$ and a pressure of $1200 \mathrm{mbar} \mathrm{H}_{2}$. The hydrogenation set-up consisted of a thermostatted double-walled glass reactor, equipped with baffles and a gas-tight mechanical stirrer with a hollow shaft and blades for gas recirculation. The reactor was loaded with tetradecane as internal standard (4.57 g; Acros; 99\%), the catalyst and the solvent (100 mL 2-propanol with $17.5 \mathrm{~mL}$ demineralized water). The amount of catalyst was $0.3 \mathrm{~g}$ for Pt/CNF (ALD) and Pt/CNF-973 (ALD) and $1 \mathrm{~g}$ for the other catalysts to ensure a constant amount of catalytic metal in the reactor. The stirrer was switched on (1700 rpm) and the slurry was saturated with $\mathrm{H}_{2}$ for $30 \mathrm{~min}$. Next, $t$-cinnamaldehyde (1.65 g; Acros; p.a.) was added and the reaction was run for $5 \mathrm{~h}$. Samples were taken at different time intervals. The samples were analyzed on a Shimadzu GC 2010 equipped with auto injector, FID detector and CP WAX 52 CB column. The conversion of cinnamaldehyde (CALD) and selectivity to cinnamyl alcohol (CALC) were calculated as described earlier [20]:

Conversion $(t)=\frac{([\operatorname{CALD}(0)]-[\operatorname{CALD}(t)])}{[\operatorname{CALD}(0)]} \times 100 \%$

$\operatorname{Selectivity}(t)=\frac{[\operatorname{CALC}(t)]}{([\operatorname{CALD}(0)]-[\operatorname{CALD}(t)])} \times 100 \%$

The platinum weight-loading of the Pt/CNF (HDP) catalyst was analyzed using calibrated X-ray fluorescence spectroscopy (Spectro X-lab 2000). For analysis 2-4 g of the dry catalyst powder was used. The metal weight loadings of the other catalysts were determined using ICP-AES. The catalysts were treated in aqua regia at $473 \mathrm{~K}$ to dissolve the metal. Analysis was performed using a Varian Liberty series II ICP-AES apparatus. Each sample was analyzed twice and the results were averaged.

Acid-base titrations were performed using a Titralab TIM 880 apparatus. To $0.05 \mathrm{~g}$ of catalyst $60 \mathrm{~mL}$ of $0.1 \mathrm{M} \mathrm{KCl}$ was added. This slurry was titrated with a solution containing $0.01 \mathrm{M} \mathrm{NaOH}$ and $0.1 \mathrm{M} \mathrm{KCl}$. The required amount of titrant to reach $\mathrm{pH} 7.5$ was used to calculate the amount of acidic sites on the catalysts, as described by Toebes et al. [21].

TEM was performed using a Tecnai 20 FEG operating at $200 \mathrm{kV}$ and a point resolution of $2.7 \AA$. The samples were suspended in ethanol using an ultrasonic treatment and brought onto a holey carbon film on a copper grid. Based on TEM, particle size histograms were compiled. The average particles sizes were recalculated to dispersion values assuming spherical shapes and using the formula described by Scholten et al. [22]:

$D=10^{21} \times \frac{6 \times M \times \rho_{\text {site }}}{d \times \rho_{\text {metal }} \times N}$

$D$ is dispersion ( $\left.\mathrm{Pt}_{\text {surface }} / \mathrm{Pt}_{\text {total }}\right), M$ the atomic weight $(195.1 \mathrm{~g} / \mathrm{mol}$ for $\mathrm{Pt}, 101 \mathrm{~g} / \mathrm{mol}$ for $\mathrm{Ru}), \rho_{\text {site }}$ the platinum surface site density (12.5 Pt atoms $/ \mathrm{nm}^{2}, 16.3 \mathrm{Ru}$ atoms $/ \mathrm{nm}^{2}$ ) [22], $d$ is particle size $(\mathrm{nm}), \rho_{\text {metal }}$ the metal density $\left(21.45 \mathrm{~g} / \mathrm{cm}^{3}\right.$ for Pt, $12.3 \mathrm{~g} / \mathrm{cm}^{3}$ for $\mathrm{Ru})$ and $N$ the Avogadro constant giving $D=1.13 / d(\mathrm{~nm})$ for Pt and $D=1.33 / d(\mathrm{~nm})$ for Ru.

Nitrogen physisorption was performed at $77 \mathrm{~K}$ using a Micromeritics Tristar 3000 V 6.04 A. The obtained data were used to calculate the BET surface area. Prior to the physisorption measurements, the samples were dried at $473 \mathrm{~K}$ for about $14 \mathrm{~h}$ under nitrogen flow. 
Table 1

Physical properties of the catalysts

\begin{tabular}{|c|c|c|c|c|c|c|c|}
\hline & BET $\left(\mathrm{m}^{2} / \mathrm{g}\right)$ & $\begin{array}{l}\text { Metal loading } \\
\text { (wt\%) }\end{array}$ & $\begin{array}{l}\text { Average metal } \\
\text { particle size } \\
(\mathrm{nm} \text {, based on TEM) }\end{array}$ & $\begin{array}{l}\text { Dispersion } \\
\text { based on TEM }\end{array}$ & $\begin{array}{l}\mathrm{H} / \mathrm{M} \text { ratio } \\
\text { (measured using } \\
\mathrm{H}_{2} \text {-chemisorption) }\end{array}$ & $\begin{array}{l}\text { Acidic, oxygen } \\
\text { surface groups } \\
\left(\mathrm{nm}^{-2}\right)\end{array}$ & $\begin{array}{l}\text { Initial TOF } \\
\left(\times 10^{-2} \mathrm{~s}^{-1} \text {, based on }\right. \\
\text { TEM dispersion })\end{array}$ \\
\hline $\mathrm{Pt} / \mathrm{CNF}$ (HDP) & 178 & 3.0 & 1.8 & 0.63 & 0.83 & 0.17 & 5.2 \\
\hline Pt/CNF-973 (HDP) & 178 & 3.0 & 2.0 & 0.57 & 0.46 & 0.00 & 7.3 \\
\hline $\mathrm{Pt} / \mathrm{CNF}$ (ALD) & 143 & 11.0 & 3.3 & 0.34 & 0.52 & 0.15 & 9.6 \\
\hline Pt/CNF-973 (ALD) & 143 & 11.0 & 3.4 & 0.33 & 0.39 & 0.00 & 8.1 \\
\hline Ru/CNF-973 (HDP) & 178 & 2.1 & 2.2 & 0.61 & 0.81 & 0.00 & 6.7 \\
\hline Ru/CNF-973 (ALD) & 178 & 2.8 & 3.5 & 0.38 & 0.29 & 0.00 & 2.7 \\
\hline
\end{tabular}

Hydrogen chemisorption measurements were performed with pure hydrogen at $303 \mathrm{~K}$ using a Coulter Omnisorp 100CX apparatus in static volumetric mode. Before the measurement, the samples $(0.15 \mathrm{~g})$ were outgassed in situ at room temperature $\left(<10^{-3} \mathrm{~Pa}\right)$ followed by purging with helium at $373 \mathrm{~K}$ for $30 \mathrm{~min}$. Then, samples were re-reduced in flowing hydrogen at $373 \mathrm{~K}$ for $60 \mathrm{~min}$. After reduction, the samples were outgassed at $373 \mathrm{~K}$ for $30 \mathrm{~min}$ to remove hydrogen. Finally, the temperature was lowered to $303 \mathrm{~K}$ for the chemisorption measurement. The adsorption isotherm was measured twice with $1 \mathrm{~h}$ evacuation between the measurements, thus giving both total and reversible adsorption isotherms. The total amount of adsorbed hydrogen was used for further calculations. The sample was weighed after the measurement to obtain the mass corresponding to reduced and dry sample. This value was used for the calculations.

\section{Results and discussion}

Some of the physical-chemical properties of the platinum and ruthenium catalysts are summarized in Table 1 . Two different batches of CNF were used. The BET surface area was slightly different, however this difference falls within the reproducibility range of $\mathrm{CNF}$ synthesis. The metal loading for the platinum catalysts prepared via ALD resulted in $11.0 \mathrm{wt} \%$, while via HDP the metal loading resulted in $3.0 \mathrm{wt} \%$. The high metal loading obtained after ALD synthesis can be explained by the gasphase-decomposition of $\mathrm{Pt}(\mathrm{acac})_{2}$ during preparation [23]. In that way platinum does not only decompose on the oxygen surface groups of the support as desired but also directly from the gasphase without the need of adsorption sites on the support.

For the ruthenium catalysts, the metal loading was determined to be $2.1 \mathrm{wt} \%$ for the HDP prepared catalyst and $2.8 \mathrm{wt} \%$ for the ALD prepared catalyst (see Table 1 ). The metal loadings of these catalysts were much closer to each other, compared to the platinum catalysts. Apparently, $\mathrm{Ru}_{3}(\mathrm{CO})_{12}$ does not suffer from gasphase-decomposition when deposited via ALD.

Representative TEM images of the prepared samples before and after heat-treatment are depicted in Figs. 2 and 3. The particle size distributions obtained from TEM are summarized in Fig. 4 and Table 1. Platinum particle sizes for the HDP prepared catalysts were $1-3 \mathrm{~nm}$ independent of the heat-treatment while ALD resulted in platinum particles which were larger, i.e. 2-6 nm,
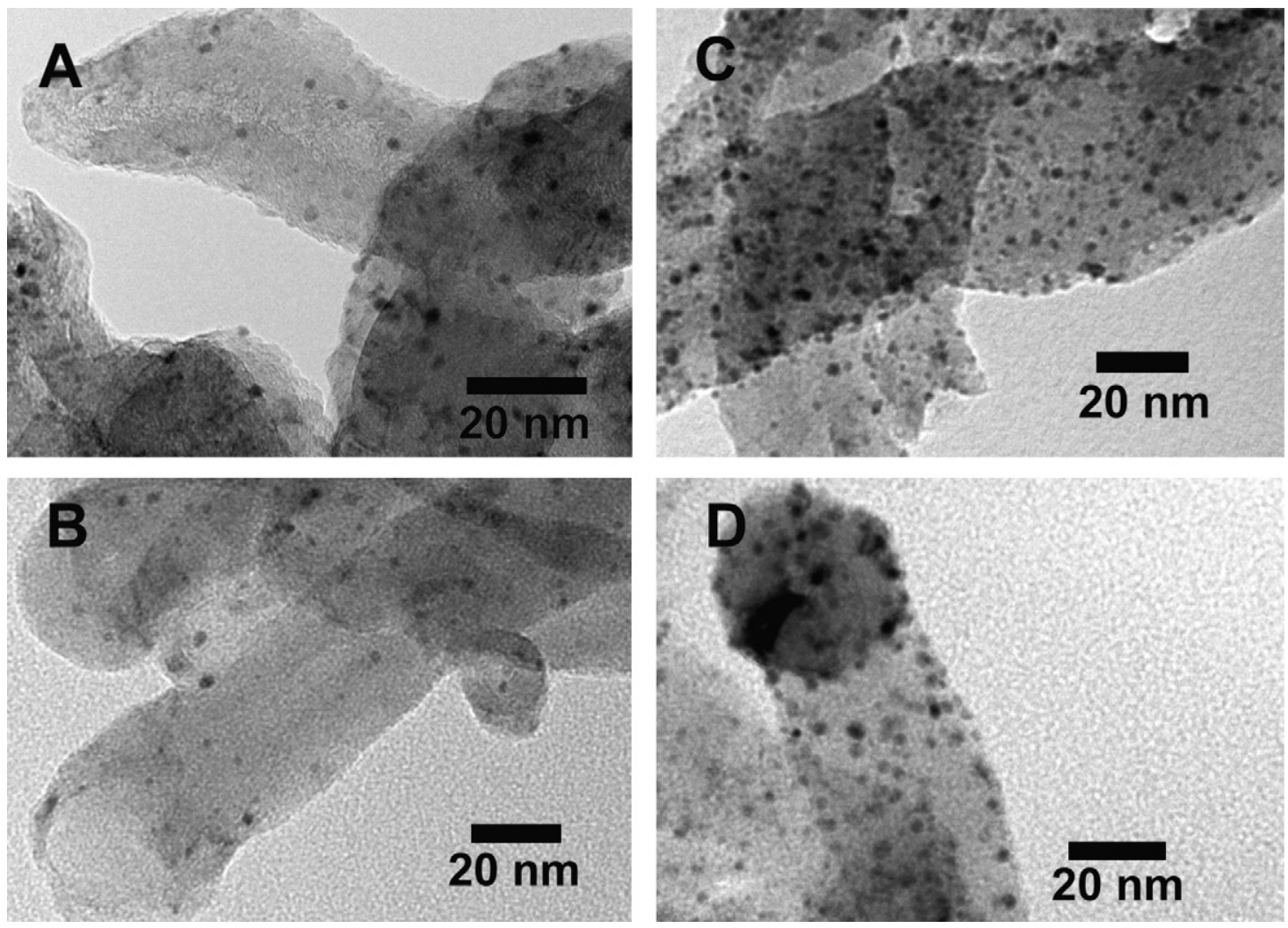

Fig. 2. TEM images of (A) Pt/CNF (HDP), (B) Pt/CNF-973 (HDP), (C) Pt/CNF (ALD), and (D) Pt/CNF-973 (ALD). 

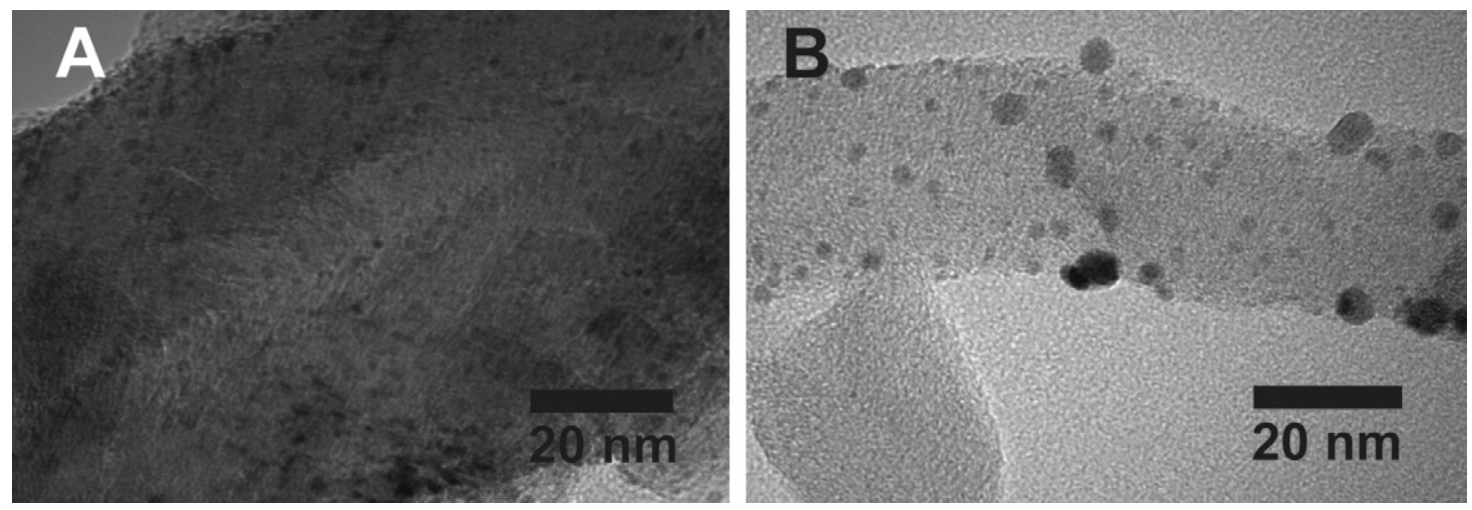

Fig. 3. TEM images of (A) Ru/CNF-973 (HDP) and (B) Ru/CNF-973 (ALD).
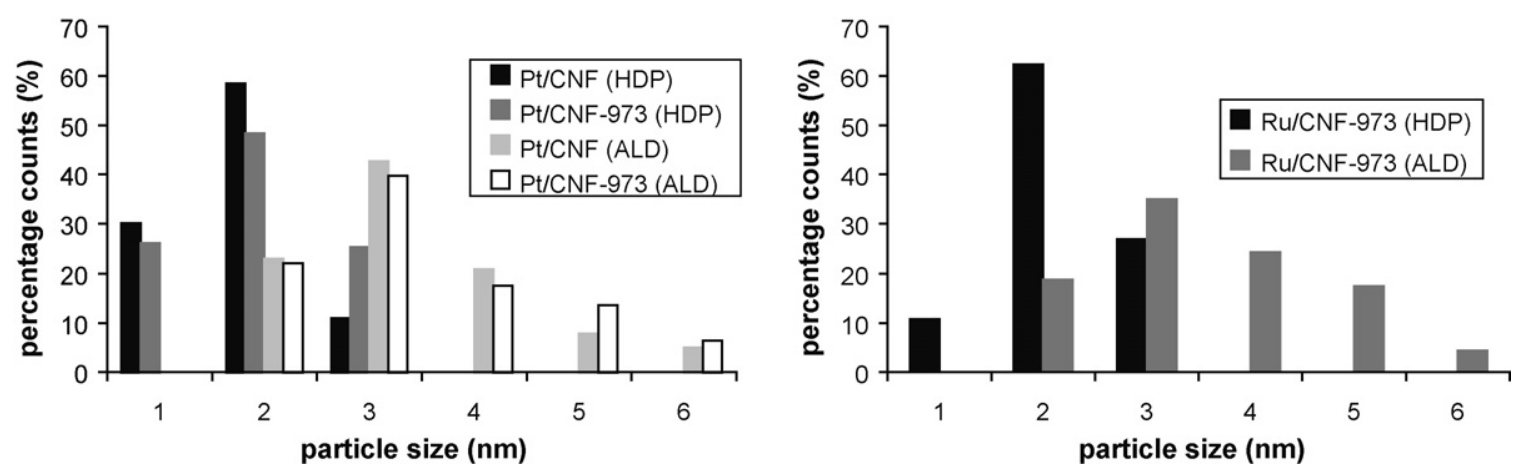

Fig. 4. TEM-based particles size histograms of the platinum catalysts (left) and ruthenium catalysts (right). Measurements are based on $90-160$ particles per sample.

irrespective whether the samples were subjected to a temperature treatment or not. Upon heat-treatment, the average particle size increased, but as already mentioned, the size range remained similar (see also Fig. 4). Also for the ruthenium samples the HDP synthesis resulted in smaller particles (1-3 nm) while ALD resulted in larger particles (2-6 nm). Hydrogen chemisorption showed that for all platinum samples the hydrogen chemisorption capacity decreased after the heat-treatments (Table 1). The results for the HDP-prepared platinum samples are in line with results obtained by Toebes et al. [14]. When the dispersions based on hydrogen chemisorption, i.e. H/M ratios, are compared to those based on TEM a clear discrepancy can be observed (Table 1). The dispersions based on TEM decreased less upon heat-treatment as compared to the hydrogen chemisorptions based dispersions which showed a strong decrease. Apparently, the hydrogen chemisorption capacity of all samples was significantly suppressed after heat-treatment. As described by Scholten et al. [22], different pre-treatments of catalysts may affect the chemical state of the metal or the support thereby changing the direct chemical environment, which has a significant influence on hydrogen chemisorption results. Moreover, it is described that the catalyst support is not necessarily inert towards chemisorbed hydrogen. Since in our case the heattreatment removes most of the oxygen groups on the CNF surface, we speculate that after heat-treatment the hydrogen spill-over is less significant resulting in a lower $\mathrm{H} / \mathrm{M}$ ratio. This might explain the large decrease of chemisorbed hydrogen after heat-treatment.

To quantify the amount of acidic oxygen surface groups $(p K a<7.5)$, acid-base titrations were performed. Fig. 5 shows typical titrations curves for Pt/CNF (HDP) and Pt/CNF-973 (HDP). Before heat-treatment, the amount of acidic, oxygen surface groups detected by titration were similar for Pt/CNF (HDP) and Pt/ CNF (ALD), i.e. $0.15-0.17$ acidic, oxygen surface groups $/ \mathrm{nm}^{2}$. After heat-treatment, all these groups were removed for all catalysts, as can be observed in Fig. 5. The titration curve showed a slightly basic character for the heat-treated catalyst indicating that a small amount of basic groups remained on the CNF surface after heattreatment [24].

The activity of the platinum based catalysts for cinnamaldehyde hydrogenation is shown in Fig. 6. Initial turn-over frequencies (TOF) based on initial conversion and dispersions based on TEM are reported in Table 1 . TEM was used to determine the accessible metal surface area as we feel it is the most reliable technique. As argued above, the alternative, i.e. hydrogen chemisorption is less reliable. The hydrogen chemisorption capacity of the samples might be influenced by hydrogen spill-over which, in turn, might

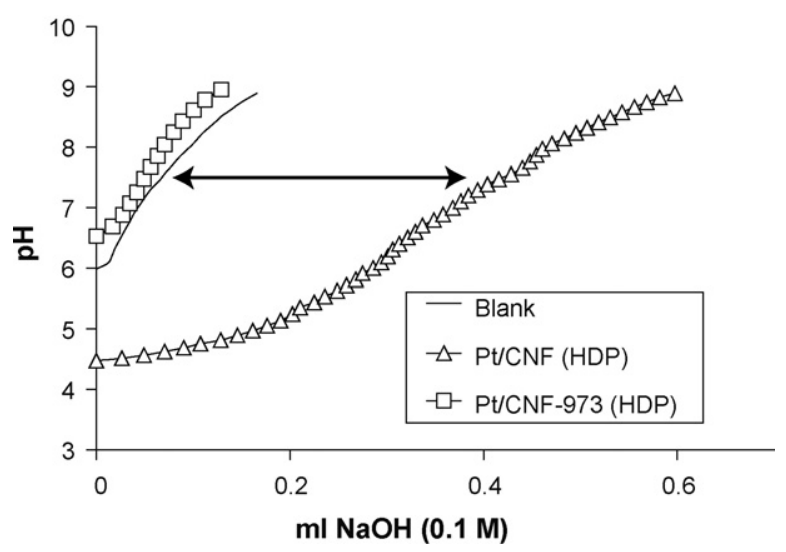

Fig. 5. Titration curves for Pt/CNF (HDP) and Pt/CNF-973 (HDP). The arrow indicates the $\mathrm{NaOH}$ consumption at $\mathrm{pH} 7.5$, which is used for the calculation of acidic groups. 

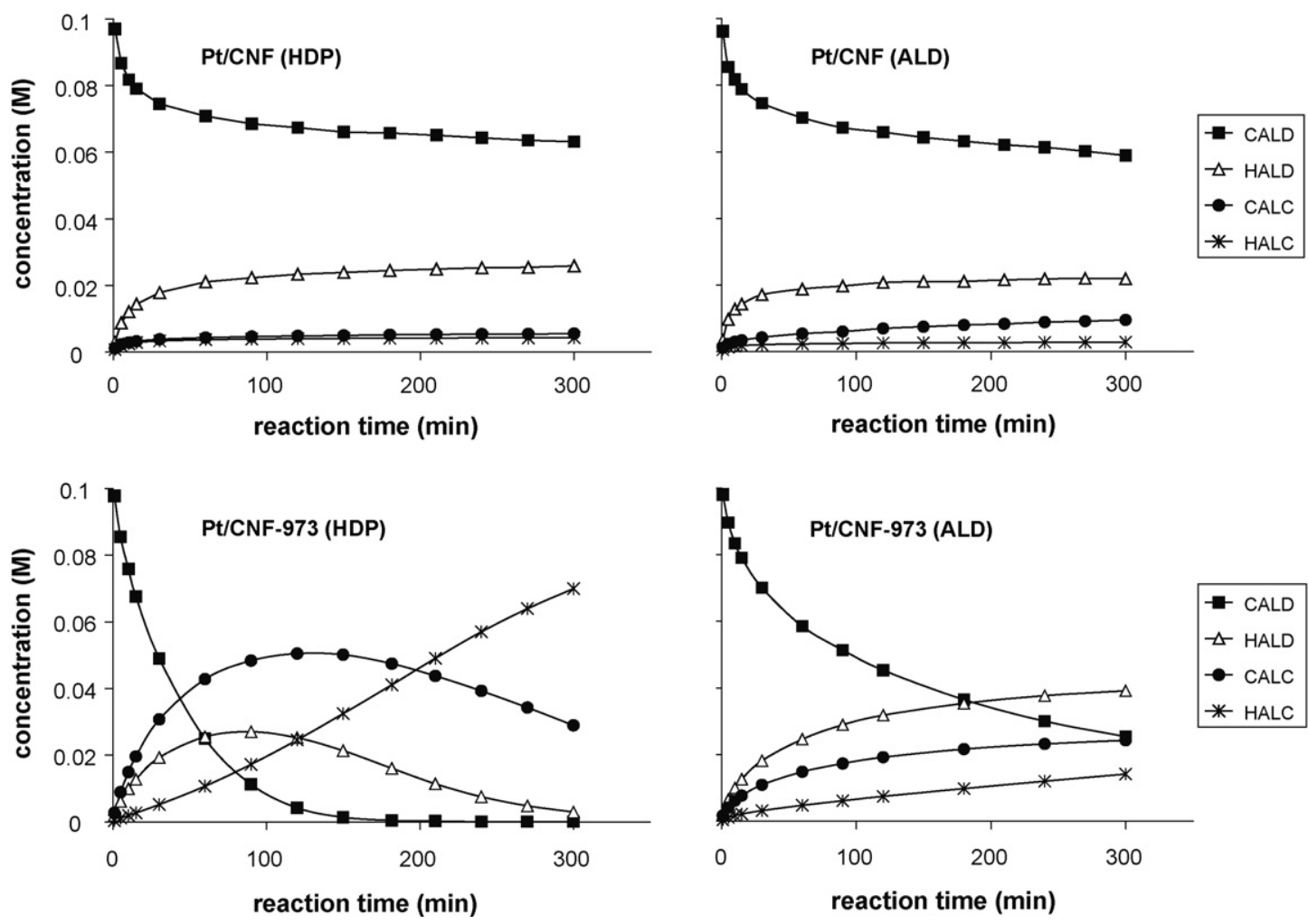

Fig. 6. Cinnamaldehyde hydrogenation results of the different platinum catalysts

depend on the support composition, i.e. presence or absence of oxygen surface groups. The abbreviations used, i.e. cinnamaldehyde (CALD), hydrocinnamaldehyde (HALD), cinnamyl alcohol (CALC) and hydrocinnamyl alcohol (HALC) are explained in Fig. 7. Please, note that CALC is the desired product.

$\mathrm{Pt} / \mathrm{CNF}$ (HDP) and Pt/CNF (ALD) reached only about 25\% conversion after 300 min forming HALD as the major product. Since the calculated TOF shows that initial activity is within the same range for all catalysts, while the activity of Pt/CNF (HDP) and $\mathrm{Pt} / \mathrm{CNF}$ (ALD) levelled off, we concluded that deactivation of the latter catalysts occurred (Fig. 6). After heat-treatment, the activity of all samples increased as was also shown previously by Toebes et al. [14]. Pt/CNF-973 (HDP) converted all CALD within 150 min and Pt/CNF-973 (ALD) converted 70\% of CALD in $300 \mathrm{~min}$. Pt/CNF973 (ALD) converted the majority of CALD into HALD, while for Pt/ CNF-973 (HDP) the selectivity changed from initially CALC ( $m a x$

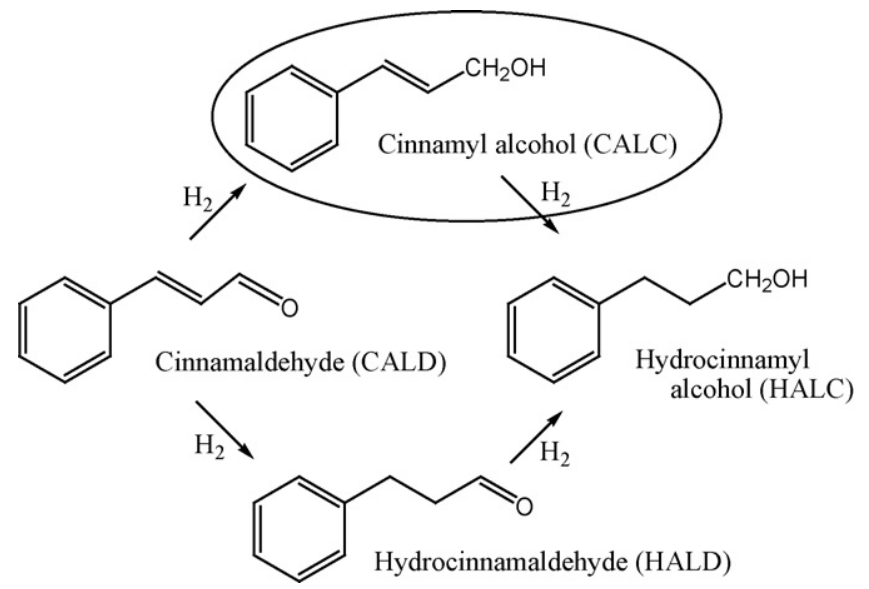

Fig. 7. Hydrogenation pathway of cinnamaldehyde, the desired product is encircled.
$59 \%$ ) as primary product to the final product HALC after longer reaction time (120 min on stream). In Fig. 8 the conversion of CALD is plotted versus the selectivity to CALC. The selectivities of the non heat-treated catalysts were in the same range and independent of the CALD conversion for Pt/CNF (HDP), thereby suggesting that deactivation did not influence the selectivity to a large extend. For $\mathrm{Pt} / \mathrm{CNF}$ (ALD) an increasing selectivity with conversion is observed, thereby exceeding the selectivity of Pt/CNF (HDP) at higher conversions. We cannot explain the observed selectivity increase at higher CALD conversions. Nevertheless, upon heat-treatment, the selectivity was significantly enhanced and Pt/CNF-973 (HDP) showed the highest selectivity and activity.

For all tested catalysts it is observed during CALD conversion that small amounts of by-products (less than $2 \%$ ) were formed. The byproducts were mainly ethylbenzene and propylbenzene. Only for Pt/ CNF (ALD) $6 \%$ of by-products was observed. The non heat-treated

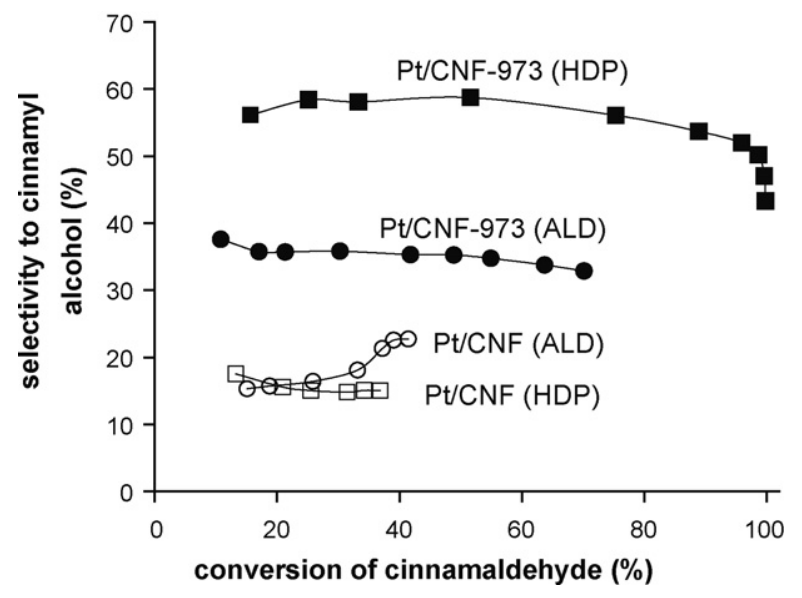

Fig. 8. Conversion vs. selectivity plot of the platinum catalysts. 

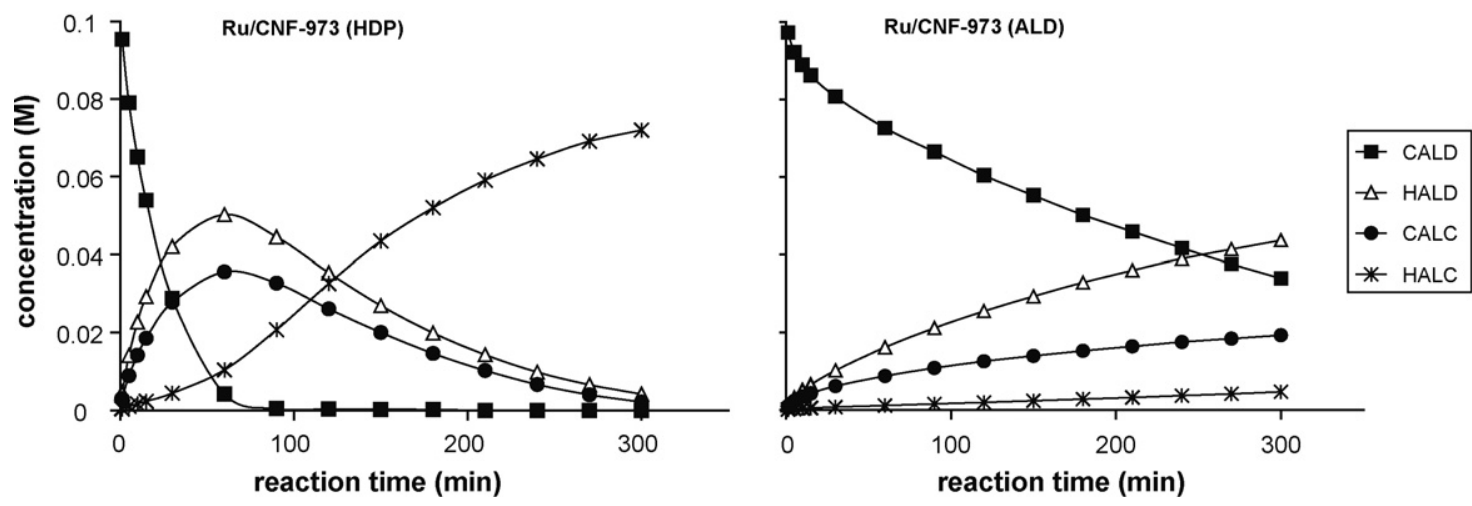

Fig. 9. Cinnamaldehyde hydrogenation results of the ruthenium catalysts.

catalysts resulted in the highest amounts of ethylbenzene, i.e. 0.3\% for both platinum catalysts. After heat-treatment, Pt/CNF-973 (ALD) resulted in $0.2 \%$ ethylbenzene whereas for Pt/CNF-973 (HDP) ethylbenzene was not observed at all. The process of decarbonylation is also associated with catalytic deactivation for liquid-phase hydrogenations and may therefore explain the observed deactivation for the non heat-treated catalysts in this study [25].

The activity of Ru/CNF-973 (HDP) and Ru/CNF-973 (ALD) is depicted in Fig. 9. Ru/CNF-973 (HDP) converted all CALD within 90 min, while Ru/CNF-973 (ALD) converted 65\% of CALD in $300 \mathrm{~min}$. For both catalysts HALD was the major initial product. In Fig. 10 the conversion of CALD for the ruthenium catalysts is plotted versus the selectivity to CALC. The selectivity to CALC was higher for Ru/CNF-973 (HDP) compared to Ru/CNF-973 (ALD).

The aim of this study was to investigate platinum and ruthenium particle size effects on carbon nanofibers for the cinnamaldehyde hydrogenation, while the amount of oxygen surface groups was similar for all samples. The results summarized in Table 1 show that we were successful in preparing two platinum samples, one with small (on average $1.8 \mathrm{~nm}$ ) particles (Pt/CNF (HDP)) and one with larger (on average $3.3 \mathrm{~nm}$ ) particles (Pt/CNF (ALD)) while the amount of oxygen surface groups was the same $\left(0.15-0.17\right.$ groups $\left./ \mathrm{nm}^{2}\right)$. In addition two samples were prepared with similar particle sizes but without oxygen groups on the surface: Pt/CNF-973 (HDP) and Pt/CNF-973 (ALD). For ruthenium based catalysts only two samples were prepared with different particle sizes, i.e. $2.2 \mathrm{~nm}(\mathrm{Ru} / \mathrm{CNF}-973(\mathrm{HDP}))$ versus $3.5 \mathrm{~nm}(\mathrm{Ru} /$ CNF-973 (ALD)) without oxygen groups on the surface.

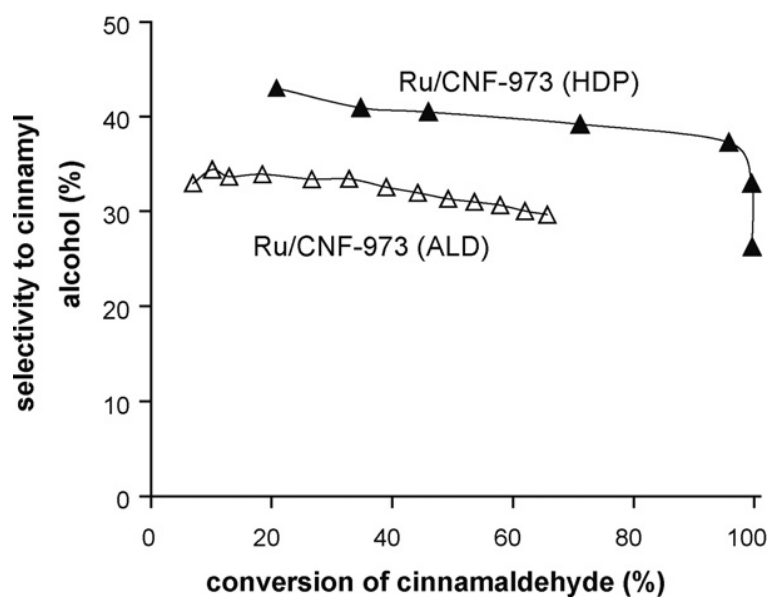

Fig. 10. Conversion vs. selectivity plot of the two ruthenium catalysts.
The catalytic tests (Fig. 8) showed that when oxygen surface groups were present large platinum particles (Pt/CNF (ALD)) resulted in a higher selectivity to CALC compared to small platinum particles (Pt/CNF (HDP)). This is fully in line with results described in literature [1]. Unexpectedly, the catalysts which were heattreated, i.e. without oxygen surface groups, showed a reversed particle size effect: small metal particles for both platinum and ruthenium catalysts resulted in a higher selectivity to cinnamyl alcohol compared to the larger metal particles (see Figs. 8 and 10). It was also observed that after heat-treatment, the activity and selectivity were strongly enhanced for the platinum catalysts (see Fig. 6).

Since the particle sizes were hardly influenced by the heattreatment, the reversed particle size effect after heat-treatment must result from the decrease in amount of oxygen groups on the support surface. In earlier work from Toebes et al. [14] it was shown that the electronic state of platinum is not significantly changed by the presence or absence of oxygen surface groups. Therefore we propose that the change in adsorption properties is the main reason for the change in catalytic behavior of the samples.

An adsorption/repulsion model is proposed to explain the reversed particle size effect and is schematically depicted in Fig. 11. The catalysts with a high amount of oxygen surface groups (i.e. non heat-treated) may repel the phenyl ring from the support surface, as described before [15]. Small metal particles on Pt/CNF (HDP) interact with the $\mathrm{C}=\mathrm{O}$ and $\mathrm{C}=\mathrm{C}$ bonds of the $\alpha, \beta$-unsaturated aldehyde group, whereas for large metal particles on Pt/CNF (ALD) the reactant phenyl ring is repelled from the polar support surface as well as from the metal surface. In the latter situation, the $\mathrm{C}=\mathrm{O}$ bond is directed towards the platinum surface [5], resulting in a higher selectivity towards cinnamyl alcohol compared to Pt/CNF(HDP) (see also Fig. 1). After removal of the oxygen surface groups, cinnamaldehyde adsorption via the phenyl ring is enhanced due to the less polar catalyst surface, resulting in a higher activity [15]. In the latter case, the reactant adsorbed in the vicinity of platinum and the metal periphery is involved in the hydrogenation as well. The reactant may direct the $\mathrm{C}=\mathrm{O}$ bond towards the metal periphery leading to an increase in selectivity and activity. This will occur for both small and larger metal particles, but the metal periphery area is much lower for the catalyst with larger particles. Therefore, the overall increase in activity and selectivity for Pt/CNF-973 (ALD) is lower compared to Pt/CNF-973 (HDP). The reversed particle size effect observed for the non-oxygen containing ruthenium catalysts are in line with the results for the non-oxygen containing platinum catalysts. Therefore, the results with ruthenium support the proposed model.

The cinnamaldehyde hydrogenation results observed for $\mathrm{Pt} /$ CNF (HDP) and Pt/CNF-973 (HDP) catalysts described in this study show an enhanced selectivity upon heat-treatment. This is the 
(A)

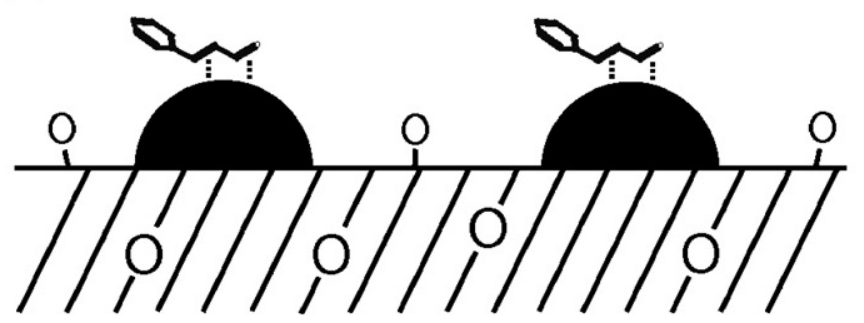

(C)

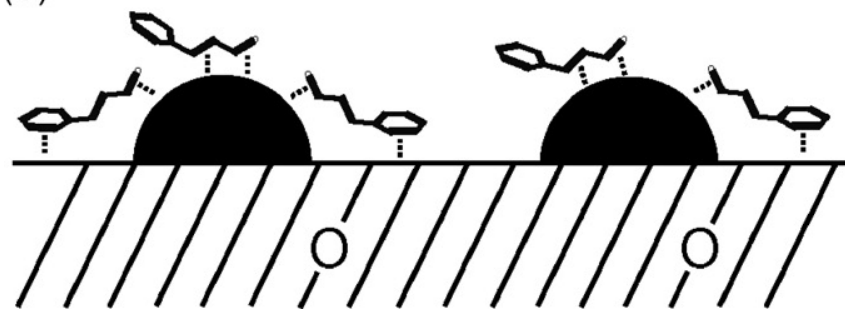

(B)

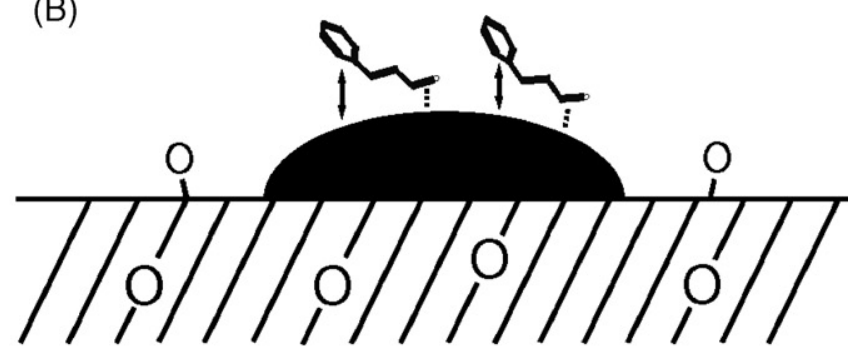

(D)

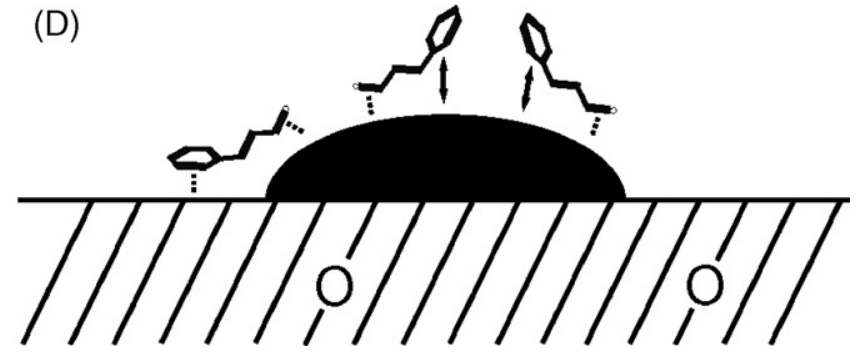

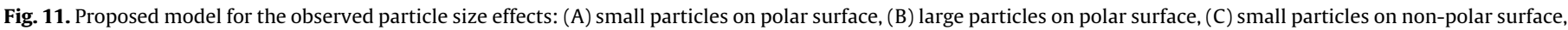
and (D) large particles on non-polar surface.

opposite trend as observed by Toebes et al. [14], who observed a decrease in selectivity upon heat-treatment. It is described in a review of Gallezot et al. [1] that for osmium-catalyzed crotonaldehyde hydrogenation the selectivity trend upon increased hydrogenation pressure may either increase or decrease depending on the support and pre-treatment. This is confirmed by Maki-Arvela et al. [26], who described in a review that for the selective hydrogenation of cinnamaldehyde the selectivity may decrease or remain constant upon increased hydrogenation pressure depending on the support used. Therefore, the observed difference in selectivity trends is ascribed to the use of different temperatures and pressures during reaction in this study and the study of Toebes et al.

\section{Conclusions}

Different sized platinum and ruthenium particles were deposited on CNF via ALD and HDP, resulting in metal particles of 2-6 nm via ALD and metal particles of $1-3 \mathrm{~nm}$ via HDP. The platinum catalysts with oxygen groups on the CNF surface showed the highest selectivity towards cinnamyl alcohol for the largest metal particles, which is in line with results described in literature. After removal of the oxygen surface groups via a heat-treatment, the smallest metal particles resulted in the highest selectivity towards cinnamyl alcohol, resulting in a reversed particle size effect compared to the catalytic results obtained with polar supports. The observed particle size effects are explained by a change in the adsorption mode of the reactant as a function of the polarity of the support. After removal of oxygen surface groups, the non-polar support favors the adsorption of the phenyl ring, which enables the metal periphery to participate in the hydrogenation. This may result in the direction of the $\mathrm{C}=\mathrm{O}$ bond to the metal periphery. For smaller metal particles, a higher metal periphery area is present and this will result in a higher increase in activity and selectivity compared to larger metal particles.

\section{Acknowledgements}

The authors acknowledge the following people: Ad Mens (nitrogen-physisorption), prof. ir. John Geus (TEM), Cor van der Spek (TEM), Marjan Versluijs (XRF), Ad van der Eerden (XRF) and
Hannu Revitzer (ICP-AES). Financial support for A.J. Plomp was provided by EU Nanocat Project 506621. Funding for H. Vuori was provided by Tekes (Finnish Funding Agency for Technology and Innovation), Neste Oil Corp. and Ecocat Corp. Support from IDECAT Network of Excellence is also acknowledged.

\section{References}

[1] P. Gallezot, D. Richard, Cat. Rev. Sci. Eng. 40 (1998) 81-126.

[2] R.G. Eilerman, R.E. Kirk, D.F. Othmer, J.I. Kroschwitz, Concise Encyclopedia of Chemical Technology, fourth ed., Wiley, New York, 1999.

[3] L. Mercadante, G. Neri, C. Milone, A. Donato, S. Galvagno, J. Mol. Catal. A: Chem. 105 (1996) 93-101.

[4] D. Richard, P. Fouilloux, P. Gallezot, in: Proceedings of the Ninth International Congress on Catalysis, vol. 3, 1988, pp. 1074-1081.

[5] A. Giroir-Fendler, D. Richard, P. Gallezot, Catal. Lett. 5 (1990) 175-182.

[6] S. Galvagno, C. Milone, G. Neri, A. Donato, R. Pietropaolo, Stud. Surf. Sci. Catal. 78 (1993) 163-170.

[7] B. Coq, P.S. Kumbhar, C. Moreau, P. Moreau, M.G. Warawdekar, J. Mol. Catal. 85 (1993) 215-228.

[8] S. Galvagno, G. Capannelli, G. Neri, A. Donato, R. Pietropaolo, J. Mol. Catal. 64 (1991) 237-246.

[9] M. Lashdaf, J. Lahtinen, M. Lindblad, T. Venalainen, A.O.I. Krause, Appl. Catal. A. 276 (2004) 129-137.

[10] M. Englisch, A. Jentys, J.A. Lercher, J. Catal. 166 (1997) 25-35.

[11] Y. Nitta, K. Ueno, T. Imanaka, Appl. Catal. 56 (1989) 9-22.

[12] S. Galvagno, C. Milone, A. Donato, G. Neri, R. Pietropaolo, Catal. Lett. 18 (1993) 349-355.

[13] B. Coq, F. Figueras, P. Geneste, C. Moreau, P. Moreau, M. Warawdekar, J. Mol. Catal. 78 (1993) 211-226

[14] M.L. Toebes, Y. Zhang, J. Hájek, T.A. Nijhuis, J.H. Bitter, A.J. van Dillen, D.Y. Murzin, D.C. Koningsberger, K.P. de Jong, J. Catal. 226 (2004) 215-225.

[15] M.L. Toebes, T.A. Nijhuis, J. Hájek, J.H. Bitter, A.J. van Dillen, D.Y. Murzin, K.P. de Jong, Chem. Eng. Sci. 60 (2005) 5682-5695.

[16] K.P. de Jong, J.W. Geus, Cat. Rev. Sci. Eng. 42 (2000) 481-510.

[17] G.L. Bezemer, P.B. Radstake, V. Koot, A.J. van Dillen, J.W. Geus, K.P. de Jong, J. Catal. 237 (2006) 291-302.

[18] M.L. Toebes, J.H. Bitter, A.J. van Dillen, K.P. de Jong, Catal. Today 76 (2002) 33-42.

[19] M.L. Toebes, F.F. Prinsloo, J.H. Bitter, A.J. van Dillen, K.P. de Jong, J. Catal. 214 (2003) 78-87.

[20] T. Vergunst, PhD thesis, Delft University of Technology, Delft, 1999.

[21] M.L. Toebes, J.M.P. van Heeswijk, J.H. Bitter, A.J. van Dillen, K.P. de Jong, Carbon 42 (2004) 307-315.

[22] J.J.F. Scholten, A.P. Pijpers, M.L. Hustings, Catal. Rev. Sci. Eng. 27 (1985) 151-206.

[23] M. Utriainen, M. Kroger-Laukkanen, L.S. Johansson, L. Niinisto, Appl. Surf. Sci. 157 (2000) 151-158.

[24] H.P. Boehm, Carbon 32 (1994) 759-769.

[25] P. Maki-Arvela, N. Kumar, K. Eranen, T. Salmi, D.Y. Murzin, Chem. Eng. J. 122 (2006) 127-134.

[26] P. Maki-Arvela, J. Hajek, T. Salmi, D.Y. Murzin, Appl. Catal. A. 292 (2005) 1-49. 